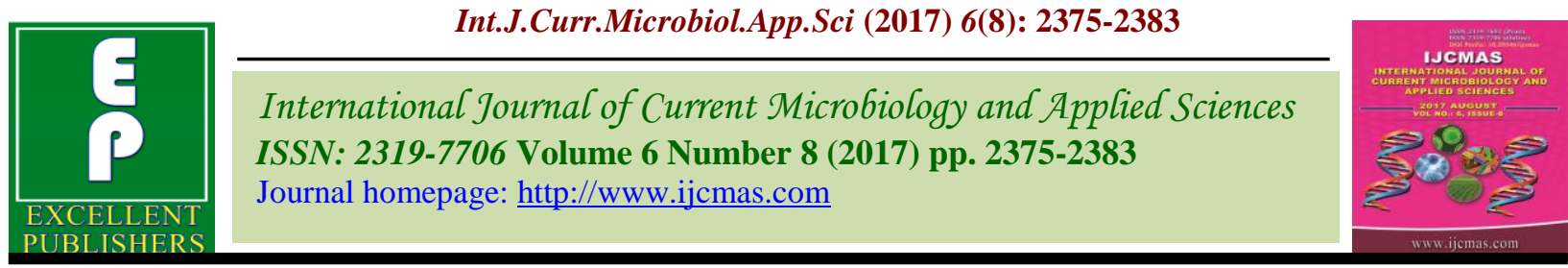

Original Research Article

https://doi.org/10.20546/ijcmas.2017.608.281

\title{
Effect of Different Harvesting and Threshing Methods on Seed Quality of Rice Varieties
}

\author{
M. Govindaraj ${ }^{1}$, P. Masilamani ${ }^{1 *}$, D. Asokan ${ }^{1}$, P. Rajkumar ${ }^{1}$ and P. Selvaraju ${ }^{2}$ \\ ${ }^{1}$ Agricultural Engineering College and Research Institute, TNAU, Kumulur-621 712, \\ Tiruchirappalli, Tamil Nadu, India \\ ${ }^{2}$ Seed centre, Tamil Nadu Agricultural University, Coimbatore-641 003 Tamil Nadu, India \\ *Corresponding author
}

\section{A B S T R A C T}

Keywords

Rice, Harvesting,

Threshing,

Mechanical

damage,

Germination,

Seedling vigour.

Article Info

Accepted:

21 June 2017

Available Online:

10 August 2017
An experiment was conducted to find out the influence of harvesting and threshing methods on seed quality of rice varieties viz., CR1009 Sub1, IW Ponni and CO51. The treatments are manual harvesting and manual threshing, manual harvesting and mechanical threshing (axial flow thresher) and combine harvesting (with pneumatic wheel). The harvested and threshed rice seeds were evaluated in terms of moisture content, kernel to husk ratio, hardness and mechanical damage based on physical, physiological and chemical methods. The results revealed that rice seed harvested and threshed through manual method or by combine harvesting method with minimum mechanical damage did not affect the germination and seedling vigour irrespective of the varieties studied.

\section{Introduction}

Rice is the main food of the largest population of the World. About $90 \%$ rice in the world is grown and consumed by the population of the Asian countries which constitute $58 \%$ population of the World. In India, it occupies an area of 43.75 mha with a production of 85.3 million tonnes. The average productivity of rice is $2.13 \mathrm{t} / \mathrm{ha}$ in India, which is far below the world's average of $3.7 \mathrm{t} /$ ha (Jagtap et al., 2012). In India, the demand for rice will increase because of population growth and an expected diet change. The country has to produce about 130 million tonnes of rice by 2025 to feed the ever growing population. Meeting the food demand of a rapidly increasing global population is emerging as a big challenge to mankind. The population is expected to grow to 9.1 billion by the year 2050, and about $70 \%$ extra food production will be required to feed them (Godfray et al., 2010; Hodges et al., 2011; Parfitt et al., 2010). The majority of this population rise is expected to be attributed mainly from developing countries, several of which are already facing issues of hunger and food insecurity.

Increasing urbanization, climate change and land use for non-food crop production, will intensify these concerns of increasing food demands. In the last few decades, most of the countries have focused on improving their 
agricultural production, land use, and population control as their policies to cope with this increasing food demand. Farm mechanization in our country has the obvious advantages of reduction in human drudgery, reduction in cost of cultivation, enhancement of working efficiency and timeliness of working.

Different types of farm operations starting from land preparation to seed storage are involved in agriculture. All these operations are labour intensive and time consuming when carried out with manual labourers. Failure to complete farm operations within the stipulated time may sharply reduce the crop production. In India improved agricultural tools and equipment are estimated to contribute food production by saving in seeds (15-20\%), fertilizers (15-20\%), time (20-30\%), and labour (20-30\%) and also by increase in cropping intensity (5-20\%), and productivity (10-15\%). In developing countries, greater than $40 \%$ of the losses occur during postharvest and processing operations (Gustavsson et al., 2011). The combine harvester, or simply combine, is a machine that "combines" the tasks of harvesting, threshing and cleaning the harvested produce. The desired result is the seed or grain (of rice, corn, soybean, black gram etc.).

For seed crops, dry weather during ripening and harvesting is essential. Harvesting rice crop using combine has been widely accepted and practiced to overcome the peak demand of farm labourers and to minimise the field losses incurred during manual harvesting. However, for reasons not known our farmers hardly use combines for rice as seed crop. With the available limited information and to verify the myth, the study was initiated to assess the effect of different harvesting and threshing methods on seed quality of rice varieties.

\section{Materials and Methods}

An experiment was conducted at the Department of Applied Sciences and Engineering, Agricultural Engineering College and Research Institute, Tamil Nadu Agricultural University, Kumulur, Tiruchirappalli, Tamil Nadu during kharif, 2016 to find out the influence of harvesting and threshing methods on seed quality of rice varieties viz., CR1009 Sub1, IW Ponni and CO51. The treatments are manual harvesting and manual threshing $\left(\mathrm{T}_{1}\right)$, manual harvesting and mechanical threshing (axial flow thresher) $\left(\mathrm{T}_{2}\right)$ and combine harvesting (with pneumatic wheel) $\left(\mathrm{T}_{3}\right)$.

The rice crops were harvested at physiological maturity stage. The seed moisture content (\%) and kernel to husk ratio were estimated at the time of harvest. The harvested and threshed seeds were sun dried to reduce the seed moisture content to 12 per cent (w.b) and processed using cleaner cum grader. The hardness tests (Viswanathan et al., 1997) were conducted using hardness tester. The seeds were placed in their natural resting position on the pressing disc. In this method a screwable rod was used to press the seed against the disc while a pointer attached to the pressing disc denotes the pressure applied in kgf. As soon as the seed cracks, a red pointer moving along with the black one stays at the cracking pressure point, while the black one moves back to the resting position.

The pressure in kgf denoted by the red pointer is taken as the hardness measurement of the seeds. The mean is expressed in kgf. Treatment wise mechanical damage was evaluated through physical, physiological and chemical methods. In the physical, method visual observations were made for splits or cracks in seed coat under illumination board. The percentage of seed coat damaged seeds was calculated using the following formula: 
Seed coat

Seed coat damaged seeds $(\mathrm{g})$

Damaged seed $\%=$ X 100

Total quantity of cleaned seed $(\mathrm{g})$

In chemical method the mechanical damage to seed was detected by ferric chloride test (Agrawal, 1995). Twenty per cent Ferric Chloride $\left(\mathrm{FeCl}_{3}\right)$ solution was prepared by adding four parts of water to one part of solution $\mathrm{FeCl}_{3}$. Five replications with 100 seeds of each treatment were soaked in $20 \%$ solution of $\mathrm{FeCl}_{3}$ for fifteen minutes. Enough $\mathrm{FeCl}_{3}$ solution was poured to immerse the seeds in the solution. Separation of black stained seeds was started within five minutes and completed within fifteen minutes after soaking. By counting the number of black stained seeds, mechanical damage percentage was recorded. In physiological method, germination was tested by roll towel method (ISTA, 2011) using the 4 x 100 seeds. The experiment was laid in completely randomized block design. Fourteen days after sowing, percent germination was computed. Ten seedlings from each replication were randomly taken and root and shoot lengths were measured. The seedlings were then oven dried at $85^{\circ} \mathrm{C}$ for 24 hours and weighed. (Abdul - Baki and Anderson, 1973)

Vigour Index $=$ Percentage germination $\mathrm{x}$ Total seedling length $(\mathrm{cm})$.

The results were subjected to statistical analysis for significant difference $(\mathrm{p} \leq 0.05)$ as per Panse and Sukhatme (1995). Percentage values were transformed using arc sine values prior to statistical analysis.

\section{Results and Discussion}

The results on influence of harvesting and threshing methods on seed quality of rice varieties revealed that the moisture content of the seed at the time of harvesting were
$22.50 \%, 19.72 \%$ and $19.51 \%$ in CO51, CR1009 Sub 1 and improved white ponni, respectively (Table 1). Among the varieties, there was no significant difference in the percent of husk and kernel to the whole seed and its ratio (Table 2). The difference in the hardness of seeds of three varieties was not statistically significant and also it was not significantly affected by different harvesting methods (Table 3, Fig. 2). In general, seed harvested and threshed by manual method recorded higher hardness when compared to manual harvesting and mechanical threshing and combine irrespective of the varieties studied. This might probably due to manual method of threshing seeds escaped from mechanical damage, whereas mechanical threshing and combine harvesting, impact by objects or rotating drums, or impact by cylinders or rotors with rasp bars, peg teeth, or wire loops. As threshing becomes more mechanized, the rasp bar type of cylinders or rotors usually rotate with tight clearance inside a concave grate that allows a shearing action and quick release of threshed kernels to fall away from the cylinder or rotor. As the kernels are released the threshed plant material is carried away, tangential to the cylinder direction of rotation.

In mechanical threshing, the rotational speed which creates impact on kernels and the clearance between the cylinder and rotor to the concave are critical settings. Many studies had emphasized that moisture content during harvest decides the intensity of mechanical injury caused by the harvester and processing equipment in paddy (Arvinder et al., 2001; Alizadeh and Khodabakhshipour, 2010).

Significant difference in percentage of mechanical injury were observed among the varieties and in seeds harvested by different harvesting methods. Among the varieties, physical observations shows the highest mechanical injury in improved white ponni 
(8.4\%) and CO51 (7.2\%), which was on par with each other and the lowest mechanical damage was observed in CR1009 Sub 1 (5.2\%), while chemical method of detection revealed that maximum mechanical injury in improved white ponni (10.3\%), while the lowest was in CR1009 Sub 1 (7.3\%) and CO51 (7.8\%). Among the different harvesting and threshing methods, physical observations shows the highest mechanical injury in manual harvesting and mechanical threshing $(8.6 \%)$ followed by combine harvesting (7.8\%) which was on par with each other, while manual harvesting and threshing registered the lowest injury of $4.4 \%$. Similar trend in mechanical injury due to different harvesting methods was also observed in chemical method of detection (Table 4, Fig. $1)$.

Fig.1 Effect of different harvesting and threshing methods on mechanical damage (\%) of Different rice varieties

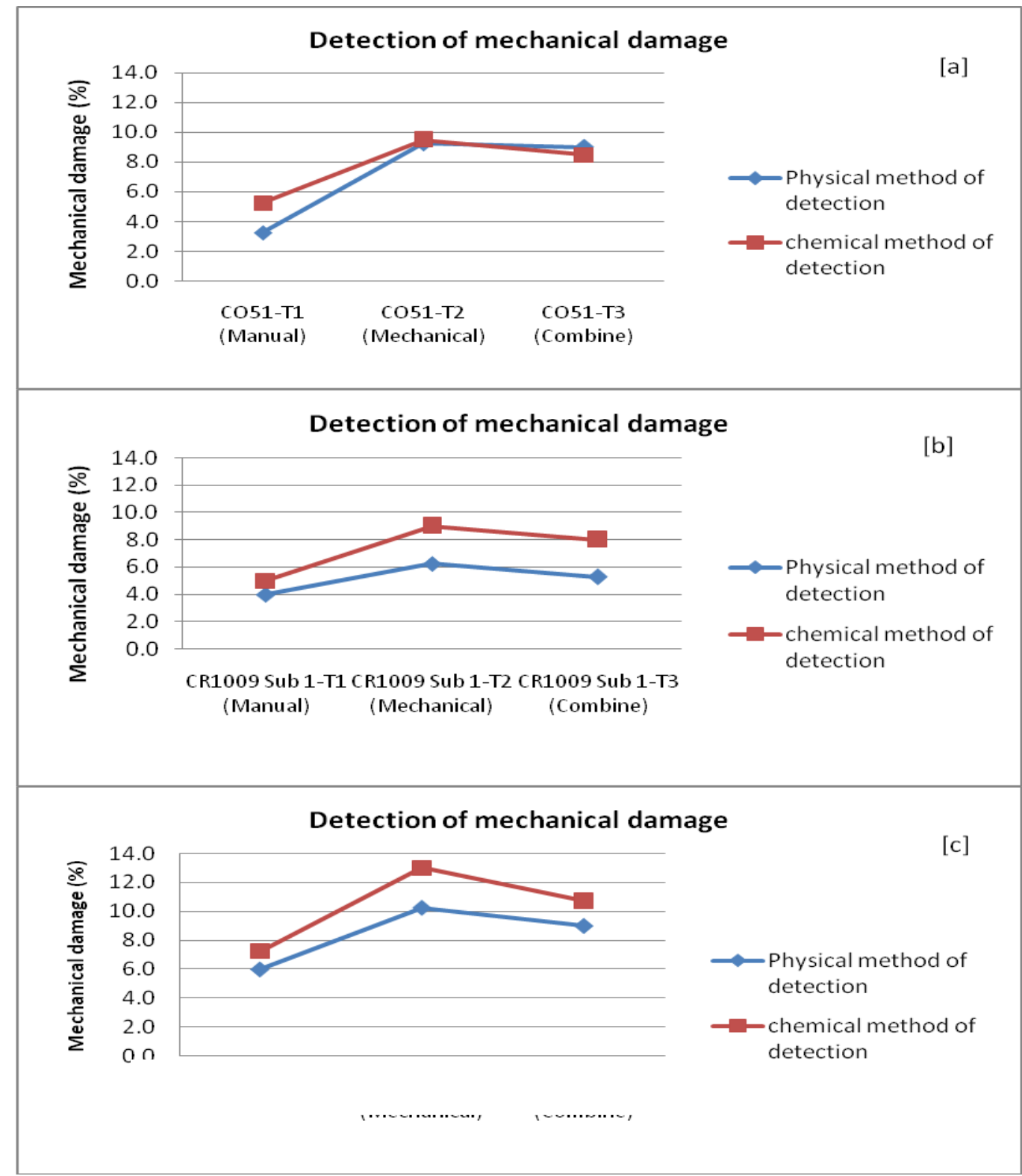

Note: [a]-CO51, [b] - CR1009 Sub 1 and [c]-Improved white ponni 
Fig.2 Effect of different harvesting and threshing methods on hardness test (Kgf) of different rice varieties
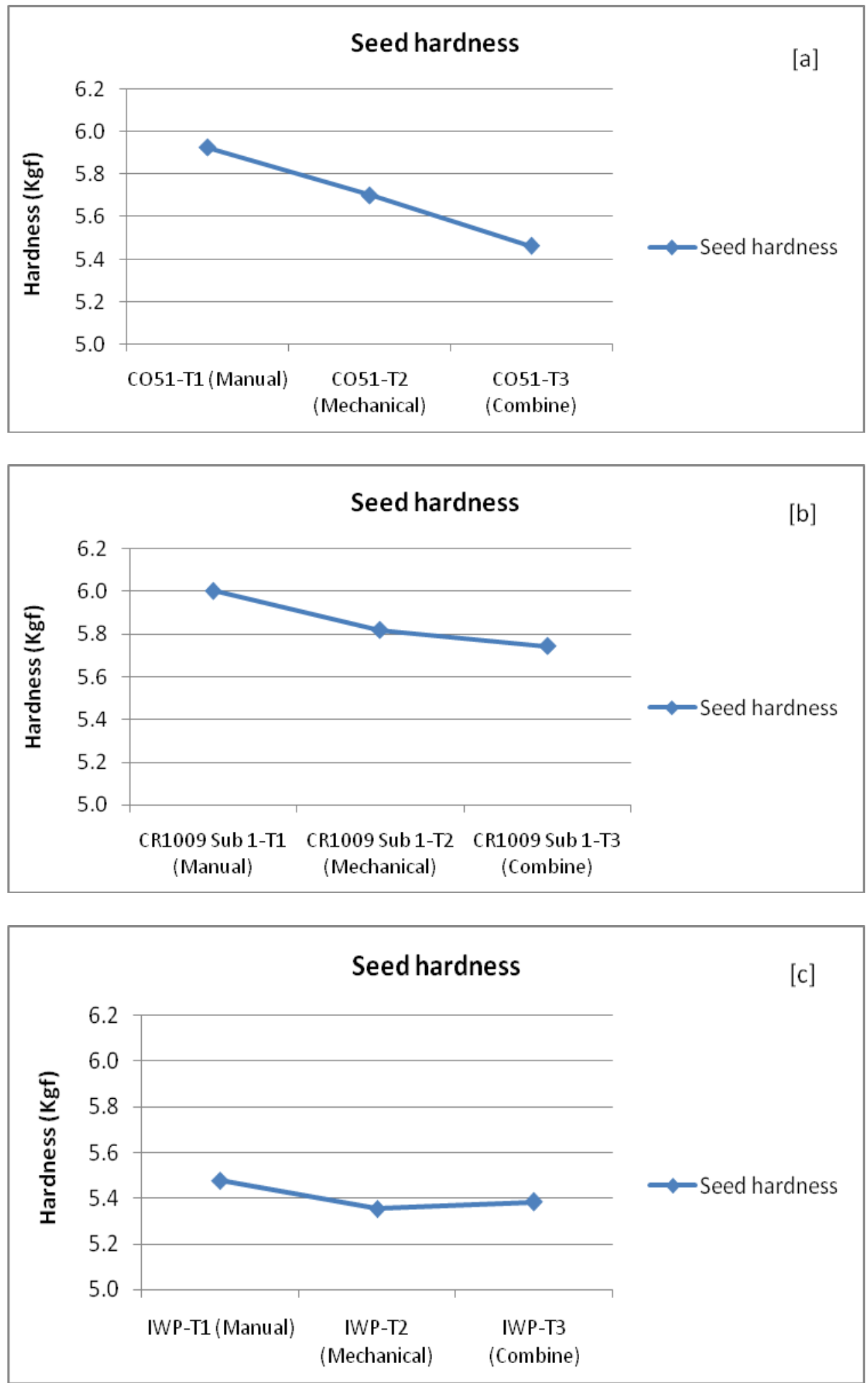

Note: [a]-CO51, [b] - CR1009 Sub 1 and [c]-Improved white ponni 
Table.1 Moisture content (\%) of different rice varieties during harvesting

\begin{tabular}{lc}
\hline \multicolumn{1}{c}{ Rice varieties } & Moisture content $(\%)$ \\
\hline CO51 $\left(\mathrm{V}_{1}\right)$ & $22.50(28.32)$ \\
CR1009 Sub 1 $\left(\mathrm{V}_{2}\right)$ & $19.72(26.36)$ \\
Improved white ponni $\left(\mathrm{V}_{3}\right)$ & $19.51(26.21)$ \\
Mean & $20.58(26.96)$ \\
\hline SEd & 0.263 \\
CD $(\mathrm{P}=0.05)$ & 0.547 \\
\hline
\end{tabular}

(Figures in parenthesis indicate arcsine value)

Table.2 Kernel and Husk percentage and their ratio for rice varieties

\begin{tabular}{lccc}
\hline \multicolumn{1}{c}{ Rice variety } & Husk $(\%)$ & Kernel $(\%)$ & Kernel to husk ratio \\
\hline CO51 $\left(\mathrm{V}_{1}\right)$ & $21.96(27.95)$ & $78.04(62.06)$ & 3.55 \\
CR1009 Sub 1 $\left(\mathrm{V}_{2}\right)$ & $22.72(28.47)$ & $77.28(61.54)$ & 3.41 \\
Improved white ponni $\left(\mathrm{V}_{3}\right)$ & $21.35(27.52$ & $78.65(62.48)$ & 3.68 \\
Mean & $22.01(27.98)$ & $77.99(62.02)$ & 3.54 \\
\hline SEd & 0.440 & 0.440 & 0.119 \\
CD $(\mathrm{P}=0.05)$ & NS & NS & NS \\
\hline
\end{tabular}

(Figures in parenthesis indicate arcsine value)

Table.3 Effect of different harvesting and threshing methods on Seed hardness for rice varieties tested

\begin{tabular}{lcccc}
\hline \multicolumn{1}{c}{ Varieties (V) } & T1 & T2 & T3 & Mean \\
\hline CO51 (V1) & 5.926 & 5.701 & 5.463 & 5.697 \\
CR1009 Sub 1 (V2) & 6.003 & 5.820 & 5.743 & 5.855 \\
Improved white ponni (V3) & 5.478 & 5.354 & 5.383 & 5.405 \\
Mean & 5.802 & 5.625 & 5.529 & 5.652 \\
\hline \multicolumn{2}{c}{ V } & T & V $\times$ T \\
SEd & 0.147 & NS & 0.255 \\
CD $(\mathrm{P}=0.05)$ & $\mathrm{NS}$ & $\mathrm{NS}$ & $\mathrm{NS}$ \\
\hline
\end{tabular}

T1-Manual harvesting and threshing, T2-Manual harvesting and mechanical threshing, T3-Combine harvesting

Table.4 Effect of different harvesting and threshing methods on mechanical damage (\%) of Different rice varieties

\begin{tabular}{|c|c|c|c|c|c|c|c|c|}
\hline \multirow{3}{*}{$\begin{array}{l}\text { Treatment }(\mathrm{T}) \\
\text { Varieties }(\mathrm{V}) \\
\end{array}$} & \multicolumn{8}{|c|}{ Mechanical damage (\%) } \\
\hline & \multicolumn{4}{|c|}{ Physical method } & \multicolumn{4}{|c|}{ Chemical method } \\
\hline & $\mathrm{T} 1$ & $\mathrm{~T} 2$ & T3 & Mean & $\mathrm{T} 1$ & $\mathrm{~T} 2$ & T3 & Mean \\
\hline \multirow{5}{*}{$\begin{array}{l}\text { CO51 (V1) } \\
\text { CR1009 Sub } 1 \\
\text { (V2) } \\
\text { Improved White } \\
\text { Ponni(V3) }\end{array}$} & $\begin{array}{c}3.3 \\
(10.18)\end{array}$ & $\begin{array}{c}9.3 \\
(17.65)\end{array}$ & $\begin{array}{c}9.0 \\
(17.30)\end{array}$ & $\begin{array}{c}7.2 \\
(15.04)\end{array}$ & $\begin{array}{c}5.3 \\
(13.15)\end{array}$ & $\begin{array}{c}9.5 \\
(17.92)\end{array}$ & $\begin{array}{c}8.5 \\
(16.86)\end{array}$ & $\begin{array}{c}7.8 \\
(15.98)\end{array}$ \\
\hline & 4.0 & 6.3 & 5.3 & 5.2 & 5.0 & 9.0 & 8.0 & 7.3 \\
\hline & $(11.35)$ & $(14.43)$ & $(13.20)$ & (12.99) & (12.89) & $(17.45)$ & $(16.27)$ & (15.54) \\
\hline & 6.0 & 10.3 & 9.0 & 8.4 & 7.3 & 13.0 & 10.8 & 10.3 \\
\hline & (14.02) & $(18.60)$ & $(17.38)$ & $(16.67)$ & $(15.53)$ & $(21.10)$ & $(19.10)$ & (18.58) \\
\hline Mean & $\begin{array}{c}4.4 \\
(11.85)\end{array}$ & $\begin{array}{c}8.6 \\
(16.89)\end{array}$ & $\begin{array}{c}7.8 \\
(15.96)\end{array}$ & $\begin{array}{c}6.9 \\
(14.90)\end{array}$ & $\begin{array}{c}5.8 \\
(13.86)\end{array}$ & $\begin{array}{c}10.5 \\
(18.82)\end{array}$ & $\begin{array}{c}9.1 \\
(17.41)\end{array}$ & $\begin{array}{c}8.5 \\
(16.70)\end{array}$ \\
\hline \multirow{3}{*}{$\begin{array}{l}\text { SEd } \\
\text { CD }(P=0.05)\end{array}$} & V & \multicolumn{2}{|c|}{$\mathrm{T}$} & $\mathrm{V} \times \mathrm{T}$ & $\mathrm{V}$ & \multicolumn{2}{|c|}{$\mathrm{T}$} & $\mathrm{V} \times \mathrm{T}$ \\
\hline & 0.886 & \multirow{2}{*}{\multicolumn{2}{|c|}{0.886}} & 1.535 & 0.722 & \multicolumn{2}{|c|}{0.722} & 1.251 \\
\hline & 1.818 & & & NS & 1.482 & \multicolumn{2}{|c|}{1.482} & NS \\
\hline
\end{tabular}

(Figures in parenthesis indicate arcsine value)

T1-Manual harvesting and threshing, T2-Manual harvesting and mechanical threshing, T3-Combine harvesting 
Table.5 Effect of different harvesting and threshing methods on Germination (\%), root length and Shoot length of different rice varieties

\begin{tabular}{|c|c|c|c|c|c|c|c|c|c|c|c|c|}
\hline \multirow{2}{*}{$\begin{array}{l}\text { Treatment }(\mathrm{T}) \\
\text { Varieties }(\mathrm{V})\end{array}$} & \multicolumn{4}{|c|}{ Germination $(\%)$} & \multicolumn{4}{|c|}{ Root length $(\mathrm{cm})$} & \multicolumn{4}{|c|}{ Shoot length $(\mathrm{cm})$} \\
\hline & $\mathrm{T} 1$ & $\mathrm{~T} 2$ & $\mathrm{~T} 3$ & Mean & $\mathrm{T} 1$ & $\mathrm{~T} 2$ & T3 & Mean & $\mathrm{T} 1$ & $\mathrm{~T} 2$ & $\mathrm{~T} 3$ & Mean \\
\hline CO51 (V1) & $\begin{array}{c}96 \\
(79.41)\end{array}$ & $\begin{array}{c}93 \\
(75.06)\end{array}$ & $\begin{array}{c}95 \\
(78.19)\end{array}$ & $\begin{array}{c}94.7 \\
(87.11)\end{array}$ & 23.5 & 22.1 & 22.4 & 22.7 & 10.3 & 9.8 & 9.8 & 10.0 \\
\hline CR1009 Sub 1 (V2) & $\begin{array}{c}94 \\
(76.96)\end{array}$ & $\begin{array}{c}90 \\
(72.05)\end{array}$ & $\begin{array}{c}91 \\
(72.88)\end{array}$ & $\begin{array}{c}91.7 \\
(74.18)\end{array}$ & 25.3 & 23.4 & 24.3 & 24.3 & 12.1 & 11.3 & 11.5 & 11.6 \\
\hline $\begin{array}{l}\text { Improved White } \\
\text { Ponni(V3) }\end{array}$ & $\begin{array}{c}97 \\
(80.64)\end{array}$ & $\begin{array}{c}91 \\
(72.88)\end{array}$ & $\begin{array}{c}94 \\
(77.87)\end{array}$ & $\begin{array}{c}94.0 \\
(77.87)\end{array}$ & 23.8 & 22.7 & 22.9 & 23.1 & 10.4 & 9.9 & 10.0 & 10.1 \\
\hline Mean & $\begin{array}{c}95.7 \\
(80.26)\end{array}$ & $\begin{array}{c}91.3 \\
(73.90)\end{array}$ & $\begin{array}{c}93.3 \\
(76.00)\end{array}$ & $\begin{array}{c}93.4 \\
(76.72)\end{array}$ & 24.2 & 22.7 & 23.2 & 23.4 & 10.9 & 10.3 & 10.4 & 10.6 \\
\hline & $\mathrm{V}$ & & & $\mathrm{V} \times \mathrm{T}$ & $\mathrm{V}$ & $\mathrm{T}$ & & $\mathrm{V} \times \mathrm{T}$ & $\mathrm{V}$ & $\mathrm{T}$ & & $x \mathrm{~T}$ \\
\hline SEd & 2.764 & & & 4.787 & 0.500 & 0.500 & & 0.867 & 0.330 & 0.330 & & 572 \\
\hline $\mathrm{CD}(\mathrm{P}=0.05)$ & NS & & & NS & $\mathrm{NS}$ & NS & & NS & 0.677 & NS & & IS \\
\hline
\end{tabular}

(Figures in parenthesis indicate arcsine value)

T1-Manual harvesting and threshing, T2-Manual harvesting and mechanical threshing, T3-Combine harvesting

Table.6 Effect of different harvesting and threshing methods on dry matter production and seedling vigour of different rice varieties

\begin{tabular}{|c|c|c|c|c|c|c|c|c|}
\hline \multirow{2}{*}{ Varieties (V) } & \multicolumn{4}{|c|}{ DMP(g/10 seedling) } & \multicolumn{4}{|c|}{ Vigour index } \\
\hline & $\mathrm{T} 1$ & $\mathrm{~T} 2$ & $\mathrm{~T} 3$ & Mean & $\mathrm{T} 1$ & $\mathrm{~T} 2$ & T3 & Mean \\
\hline CO51 (V1) & 0.079 & 0.078 & 0.079 & 0.079 & 3251 & 2965 & 3057 & 3091 \\
\hline CR1009 Sub 1 (V2) & 0.107 & 0.105 & 0.106 & 0.106 & 3519 & 3121 & 3255 & 3298 \\
\hline Improved White Ponni(V3) & 0.081 & 0.077 & 0.078 & 0.079 & 3317 & 2967 & 3087 & 3124 \\
\hline Mean & 0.089 & 0.087 & 0.088 & 0.088 & 3362 & 3017 & 3133 & 3171 \\
\hline & $\mathrm{V}$ & \multicolumn{2}{|c|}{$\mathrm{T}$} & $\mathrm{V} \times \mathrm{T}$ & $\mathrm{V}$ & \multicolumn{2}{|c|}{$\mathrm{T}$} & $\mathrm{V} \times \mathrm{T}$ \\
\hline SEd & 0.002 & \multicolumn{2}{|c|}{0.002} & 0.004 & 87.19 & \multicolumn{2}{|c|}{87.19} & 151.02 \\
\hline $\mathrm{CD}(\mathrm{P}=0.05)$ & 0.004 & \multicolumn{2}{|c|}{ NS } & NS & NS & \multicolumn{2}{|c|}{178.90} & NS \\
\hline
\end{tabular}

T1-Manual harvesting and threshing, T2-Manual harvesting and mechanical threshing, T3-Combine harvesting 
Results on physiological quality of seeds obtained by different harvesting and threshing methods in three varieties revealed that seed germination and root length of all the three varieties were not significantly influenced by the different harvesting methods in spite of significant changes in the shoot length and dry matter production among the varieties. However, vigour index values were significantly influenced by different harvesting and threshing methods. The maximum vigour index was recorded in seeds harvested and threshed manually (3362) followed by combine harvester (3133) while the minimum was observed in seeds obtained through manual harvesting and mechanical threshing (3017) (Tables 5 and 6). The above results clearly indicated that the highest mechanical injury caused by manual harvesting and mechanical threshing. Yadav and Sharma (1998) observed that the cracked seed coats reflect poor quality of seeds as they may be prone to imbibitional and pathogenic injury during storage. Hence, reduction in vigour of the seeds may result in reduction in the shelf life of the seeds. Therefore, proper adjustment of threshing machines is necessary to minimize the mechanical damage and to obtain quality seeds. In any seed production activity, achieving high level of germination is the prime objective. As per the minimum seed certification standards, rice seed should passes 80 per cent germination. In the present study, irrespective of harvesting and threshing methods of rice varieties a germination level of above 80 per cent (91-97 per cent germination) was registered.

This study clearly indicates that the paddy crop harvested and threshed either manually or by combine was with minimum mechanical damage without out impairing the germination and seedling vigour. Both harvesting and pre-cleaning operations are done simultaneously using combine harvester. Since combine harvester is designed for paddy harvest, necessary adjustment have to be done to the threshing drum and concave to increase the threshing efficiency and to minimize breakage. When paddy thresher or combine is used, care must be taken to thoroughly check the machinery for previous crop remnants to avoid seed admixture. Finally it could be concluded that manual/combine harvester is recommended for harvesting of rice varieties viz., CR1009 Sub1, IW Ponni and CO51 without impairing the germination and seedling vigour.

\section{References}

Abdul-Baki, A.A. and Anderson, J.D. 1973. Vigour deterioration of soybean seeds by multiple criteria. Crop Sci., 13: 630633.

Agrawal, R.L. 1995. Seed viability. Seed Tech. 2nd Edition: 580-582.

Ahmad, T., Mahmood, H.S. and Ali, Z. 2016. Effect of paddy harvesting methods on rice quality and head rice recovery. $J$. Eng. Appl. Sci., 11: 14519- 14523.

Alizadeh, M.R. and Khodabakhshipour, M., 2010. Effect of Threshing Drum Speed and Crop Moisture Content on the Paddy Grain Damage in Axial-Flow Thresher. Cercetari Agronomice in Moldova, 43:144.

Arvinder, S., I.K. Garg, V.K. Sharma and A. Singh, 2001. Effect of different crop and operational parameters of a combine on grain damage during paddy harvesting. $J$. of Research Punjab Agriculture University, 38: 241-52

Dorrell, D.G. and Adams, M.W., 1969. Effect of some seed characteristics on mechanically induced seed coat damage in navy beans (Phaseolus vulgaris L.). Agron. J., 61:672-673.

Gagare, K.C., Bharud, R.W., Shelar, V.R. and Karjule, A.P., 1998. Detection of mechanical damage to soybean seed surface using ferric chloride 
test. Seed, 1: 5.

Godfray, H.C.J., Beddington, J.R., Crute, I.R., Haddad, L., Lawrence, D., Muir, J.F., Pretty, J., Robinson, S., Thomas, S.M. and Toulmin, C., 2010. Food security: the challenge of feeding 9 billion people. Sci., 327: 812-818.

Gustavsson, J., Cederberg, C., Sonesson, U., Van Otterdijk, R. and Meybeck, A., 2011. Global food losses and food waste Rome: FAO. pp. 1-38.

Hodges, R.J., Buzby, J.C. and Bennett, B., 2011. Postharvest losses and waste in developed and less developed countries: opportunities to improve resource use. J. Agrl. Sci., 149:.37-45.

ISTA. 2011. International rules for seed testing. International Seed Testing Association, Bassersdorf, Switzerland.

Jagtap, D.N., Mahadkar, U.V. and Chavan, L.S., 2012. Productivity and economics of rice influenced by different crop establishment methods and fertilizer sources. Agr. J., 7:32-36.

Panse, V.G. and Sukhatme, P.V. 1995. Randomized design and square and factorial experiment in statistical methods of Agricultural workers (2 nd Edn.) ICAR, New Delhi.

Parfitt, J., Barthel, M. and Macnaughton, S., 2010. Food waste within food supply chains: quantification and potential for change to 2050. Philosophical Transactions of the Royal Society of London B: Biol. Sci., 365: 3065-3081.

Viswanathan, R., Pandiyarajan, T. and Varadaraju, N., 1997. Physical and mechanical properties of tomato fruits as related to pulping. J. Food. Sci.Tech, 34:537-539.

Yadav, S.P. and S.P. Sharma (1998). Seed coat cracking in Kabuli Gram. Seed Res. 26: $120-124$.

\section{How to cite this article:}

Govindaraj, M., P. Masilamani, D. Asokan, P. Rajkumar and Selvaraju, P. 2017. Effect of Different Harvesting and Threshing Methods on Seed Quality of Rice Varieties. Int.J.Curr.Microbiol.App.Sci. 6(8): 2375-2383. doi: https://doi.org/10.20546/ijcmas.2017.608.281 